\title{
Влияние плотности ростовых ямочных дефектов поверхности InAlAs на температурные зависимости параметров Au/Ti/n-InAlAs(001) диодов Шоттки
}

\author{
М.С. Аксенов, И.Б. Чистохин, Н.А. Валишева, Д.В. Дмитриев, К.С. Журавлев \\ Институт физики полупроводников им. А.В. Ржанова СО РАН,
}

Новосибирск, 630090, пр. Ак. Лаврентьева, 13

DOI 10.34077/RCSP2019-125

Тройное соединения InAlAs является перспективным материалом для создания СВЧфотодетекторов с барьером Шоттки (БШ) [1]. Природа формирования БШ на границе раздела металлполупроводник и связанные с ней механизмы переноса зарядов являются предметом интенсивных исследований уже несколько десятилетий, поскольку свойства этой границы раздела определяют рабочие характеристики приборов, их стабильность и надежность. Вольт-амперные характеристики (BAX) реальных БШ обычно не соответствуют идеальной модели термоэлектронной эмиссии (ТЭ). Неидеальное поведение ВАХ БШ (коэффициент идеальности больше 1) в слаболегированном (менее $10^{16} \mathrm{~cm}^{-3}$ ) полупроводнике часто связывают с наличием естественного оксидного слоя и интерфейсных ловушек. С другой стороны, в работе Танга [2] показано, что неидеальное поведение BAX может быть количественно объяснено предположением о наличии на границе раздела металл/полупроводник локально расположенных областей с пониженной высотой барьеров и линейными размерами порядка глубины области обеднения. Аргументом в пользу использования модели Танга для анализа ВАХ является проявление в экспериментах аномальной корреляционной зависимости коэффициента идеальности $(n)$ и высоты БШ $\left(\varphi_{\mathrm{b} 0}\right)$ от температуры. В большинстве работ, в которых модель Танга применяется для объяснения поведения температурных зависимостей параметров различных БШ, отсутствуют предположения о природе неоднородностей.

В данной работе изучено влияние плотности ростовых ямочных дефектов поверхности слоев InAlAs (рис. 1 а, вставка), выращенных методом молекулярно-лучевой эпитаксии на подложках $\mathrm{InP}$ (001), на температурные (78-380 К) зависимости вольт-амперных характеристик барьеров Шоттки $\mathrm{Au} / \mathrm{Ti} / \mathrm{n}$-InAlAs. Показано, что уменьшение плотности ростовые дефекты с $10^{7}$ до $10^{6} \mathrm{~cm}^{-2}$ оказывают слабое влияния на BAX при температурах выше $200 \mathrm{~K}$, которые хорошо описываются теорией ТЭ со значениями $n$ и $\varphi_{\mathrm{b} 0}$ близкими к 1.1 и 0.69 эВ, соответственно (рис. 1). В тоже время изменение плотности дефектов оказывает существенное влияние на параметры БШ при температурах ниже $200 \mathrm{~K}$, поведение которых хорошо описывается моделью Танга, предполагающей наличие на поверхности InAlAs локальных неоднородностей с пониженной высотой барьера. Сопоставление полученных данных показывает, что ростовые ямочные дефекты являются причиной возникновения таких областей.
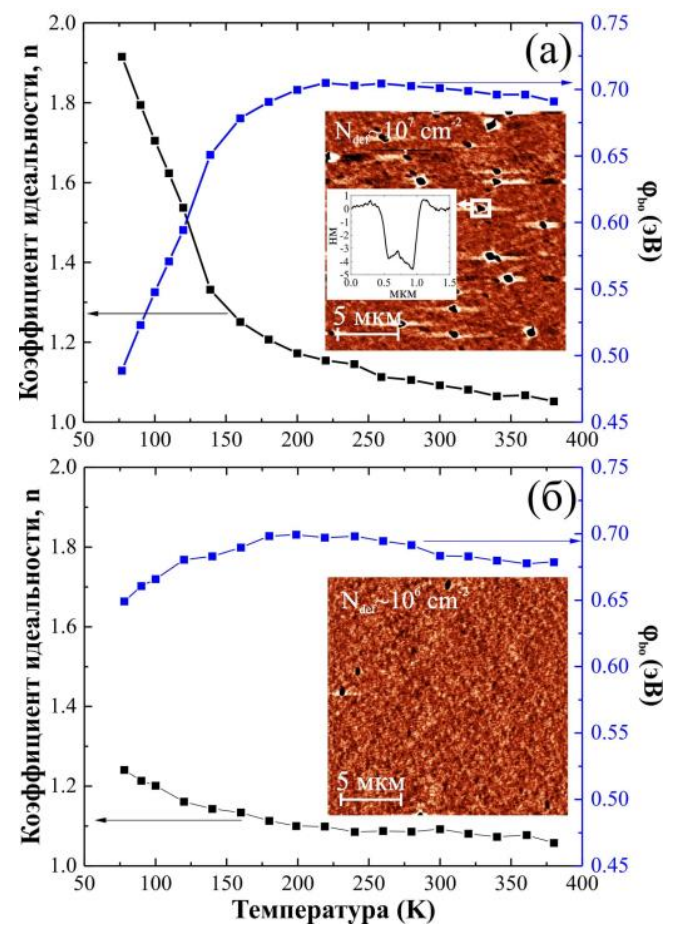

Рис. 1. Температурные зависимости $n$ и

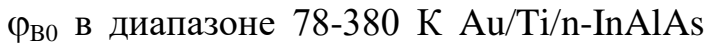
БШ, сформированных на поверхности с плотностью ростовых дефектов $10^{6}$ (а) и $10^{7} \mathrm{~cm}^{-2}$ (б). На вставках представлены 20x20 мкм АСМ-изображения поверхности InAlAs перед формированием БШ.

Исследование выполнено при финансовой поддержке РФФИ в рамках научного проекта № 18-3200548 .

\section{Лumepamypa}

[1] A. Chizh et al. High-Power InGaAs/InAlAs Schottky Photodiode with Low Amplitude-to-Phase Noise Conversion // 2018 International Topical Meeting on Microwave Photonics (MWP). 2018.

[2] R.T. Tung // Phys. Rev. B. 1992. V. 45. N. 23. P. 13509-13523. 